\title{
ANALISIS JARAK ANTAR PERLINTASAN SEBIDANG JALUR KERETA API CIKARANG - CIKAMPEK
}

\author{
Abadi Sastrodiyoto, $\mathrm{SH}, \mathrm{MH}$ \\ Dosen STTD \\ Jl. Raya Setu No. 89 Cibuntu, \\ Cibitung Bekasi 17001 \\ Telp/Fax. 0218254640 \\ Abadi_sastro@yahoo.com \\ Ir. Juliaman Pangaribuan, M.Si \\ Dosen STTD \\ Jl. Raya Setu No. 89 Cibuntu, \\ Cibitung Bekasi 17001 \\ Telp/Fax. 0218254640
}

\author{
Dr. Edi Waluyo, M.Sc \\ Dosen STTD
}

Jl. Raya Setu No. 89 Cibuntu,

Cibitung Bekasi 17001

Telp/Fax. 0218254640

\author{
Ir. Santausa Purnama, MM \\ Dosen STTD
}

J1. Raya Setu No. 89 Cibuntu,

Cibitung Bekasi 17001

Telp/Fax. 0218254640

\author{
Uriansyah, S.SiT \\ Dosen STTD \\ Jl. Raya Setu No. 89 Cibuntu, \\ Cibitung Bekasi 17001 \\ Telp/Fax.021 8254640
}

\begin{abstract}
Railways as a mode of transportation that has the characteristics and special advantages, especially in its ability to transport, both for people and goods, save energy, save the use of space, and has a high safety factor. Given the characteristics and advantages, the railways continue to be developed and carried out improvement of railway infrastructure, which is marked with had operated double rail Northern Line Jakarta - Surabaya in 2014 ago and the construction of double track South Line Jakarta - Surabaya, which is currently being worked on and targeted for completion in 2017. at this time also gradually been operated locomotives purchased by PT Kereta Api Indonesia of 100 units, and 1,000 units of flat wagons for containers, and 1,200 units of electric train. The locomotive purchases to boost rail freight, especially coal transportation in South Sumatra targeted 25 million tonnes per year in 2020 , while the purchase of flat wagons for improving freight container up to 1 million containers per year. Then purchase KRL to meet the target passenger trains in Jakarta, Bogor, Tangerang and Bekasi 1.2 million people per day by 2019. With the addition of infrastructure and facilities of railway for the transport of people and goods, will certainly result in an increased frequency of train travel from Jakarta to Bandung , Cirebon, Pekalongan, Semarang, Purwokerto, Yogyakarta, Solo , Bojonegara, Madiun to Surabaya and vice versa, especially Railroad through Cikarang - Cikampek . Railway Cikampek Cikarang or vice versa is a meeting of the railway line from the direction of the direction of Cirebon and Bandung, so the frequency is more dense than the other track. At Railway Cikarang - Cikampek there are 10 official crossings.
\end{abstract}

Keywords :railway, nfrastructure, locomotive 


\begin{abstract}
ABSTRAK
Perkeretaapian sebagai salah satu moda transportasi yang memiliki karakteristik dan keunggulan khusus, terutama dalam kemampuannya untuk mengangkut, baik untuk orang maupun barang, menghemat energi, menghemat penggunaan ruang, mempunyai faktor keselamatan yang tinggi. Mengingat karakteristik dan keunggulan tersebut, maka perkeretaapian terus dikembangkan dan dilakukan peningkatan sarana dan prasarana perkeretaapian, yang ditandai dengan telah dioperasikannya rel ganda Jalur Utara Jakarta-Surabaya pada tahun 2014 yang lalu dan pembangunan rel ganda Jalur Selatan Jakarta-Surabaya yang saat ini sedang dikerjakan dan ditargetkan selesai pada tahun 2017. Di samping itu pada saat ini juga secara bertahap telah dioperasikan lokomotif yang dibeli oleh PT Kereta Api Indonesia sebanyak 100 unit, dan 1.000 unit gerbong datar untuk peti kemas, serta 1.200 unit kereta rel listrik (KRL). Pembelian lokomotif tersebut untuk meningkatkan angkutan kereta api khususnya angkutan batu bara di Sumatera Selatan yang ditargetkan 25 juta ton per tahun pada 2020, sedangkan pembelian gerbong datar tersebut untuk meningkatkan angkutan peti kemas hingga 1 juta peti kemas per tahun. Kemudian pembelian KRL untuk memenuhi target angkutan penumpang kereta api di Jakarta, Bogor, Tangerang, dan Bekasi sebanyak 1,2 juta orang per hari pada 2019. Dengan penambahan jumlah prasarana dan sarana perkeretaapian untuk angkutan orang dan barang tersebut, tentunya akan berakibat pada peningkatan frekuensi perjalanan kereta api dari Jakarta menuju Bandung, Cirebon, Pekalongan, Semarang, Purwokerto,Yogyakarta, Solo, Bojonegara, Madiun dan Surabaya dan begitu sebaliknya, terutama yang melalui Jalur Kereta Api Cikarang-Cikampek. Jalur Kereta Api Cikampek-Cikarang atau sebaliknya tersebut merupakan pertemuan jalur kereta api dari arah Cirebon dan dari arah Bandung, sehingga frekuensinya lebih padat daripada jalur yang lainnya. Pada Jalur Kereta Api Cikarang-Cikampek terdapat 10 perlintasan sebidang resmi.
\end{abstract}

Kata kunci :Jalur kereta api, infrastruktur, lokomotif

\title{
PENDAHULUAN
}

Perkeretaapian sebagai salah satu moda transportasi yang memiliki karakteristik dan keunggulan khusus, terutama dalam kemampuannya untuk mengangkut, baik untuk orang maupun barang, menghemat energi, menghemat penggunaan ruang, mempunyai faktor keselamatan yang tinggi, memiliki tingkat pencemaran yang rendah. Di samping itu, lebih efisien dibandingkan dengan moda transportasi jalan untuk angkutan jarak jauh dan untuk daerah yang padat lalu lintasnya, seperti angkutan perkotaan.

Mengingat karakteristik dan keunggulan tersebut, maka perkeretaapian terus dikembangkan dan dilakukan peningkatan sarana dan prasarana perkeretaapian, yang ditandai dengan telah dioperasikannya rel ganda Jalur Utara Jakarta-Surabaya pada tahun 2014 yang lalu dan pembangunan rel ganda Jalur Selatan Jakarta-Surabaya yang saat ini sedang dikerjakan dan ditargetkan selesai pada tahun 2017. Di samping itu pada saat ini juga secara bertahap telah dioperasikan lokomotif yang dibeli oleh PT Kereta Api Indonesia sebanyak 100 unit, dan 1.000 unit gerbong datar untuk peti kemas, serta 1.200 unit kereta rel listrik (KRL).

Pembelian lokomotif tersebut untuk meningkatkan angkutan kereta api khususnya angkutan batu bara di Sumatera Selatan yang ditargetkan 25 juta ton per tahun 
pada 2020, sedangkan pembelian gerbong datar tersebut untuk meningkatkan angkutan peti kemas hingga 1 juta peti kemas per tahun. Kemudian pembelian KRL untuk memenuhi target angkutan penumpang kereta api di Jakarta, Bogor, Tangerang, dan Bekasi sebanyak 1,2 juta orang per hari pada 2019.

Pada tanggal 31 Januari 2015 belum lama ini telah diluncurkan Kereta Api Kontainer KALOG-6 dari Stasiun Gede Bage, Bandung ke Stasiun Pasoso, Tanjung Priok, Jakarta. KALOG-6 ini akan beroperasi setiap hari melanyani angkutan peti kemas BandungJakarta pp, sebagai tambahan operasi KALOG lainnya yang sudah beroperasi JakartaSurabaya pp.

Di samping itu, mulai tanggal 1 April 2015 PT Kereta Api Indonesia (PT KAI) telah menambah 74 jadwal perjalanan kereta api, sebanyak 50 jadwal perjalanan untuk penumpang dan sebanyak 24 jadwal perjalanan untuk barang yang dituangkan dalam Grafik Perjalanan Kereta Api (Gapeka) 2015. Untuk Jabodetabek penambahan jadwal perjalanan kereta api tersebut, yaitu Bekasi 2 kali perjalanan, Serpong 1 kali perjalanan, dan Tangerang Line 1 kali perjalanan. Penambahan jumlah jadwal perjalanan kereta api tersebut, diharapakan dapat menambah jumlah perpindahan penumpang dan barang dari kendaraan pribadi dan angkutan truk ke kereta api (Kompas, 18 Februari 2015 hal 19).

Dengan penambahan jumlah prasarana dan sarana perkeretaapian untuk angkutan orang dan barang tersebut, tentunya akan berakibat pada peningkatan frekuensi perjalanan kereta api dari Jakarta menuju Bandung, Cirebon, Pekalongan, Semarang, Purwokerto,Yogyakarta, Solo, Bojonegara, Madiun dan Surabaya dan begitu sebaliknya, terutama yang melalui Jalur Kereta Api Cikarang-Cikampek. Jalur Kereta Api CikampekCikarang atau sebaliknya tersebut merupakan pertemuan jalur kereta api dari arah Cirebon dan dari arah Bandung, sehingga frekuensinya lebih padat daripada jalur yang lainnya. Pada Jalur Kereta Api Cikarang-Cikampek terdapat 10 perlintasan sebidang resmi.

\section{METODE}

Model penelitian yang dipergunakan dalam penelitian ini adalah melakukan pembandingan antara teori atau peraturan perundang-undangan dengan kondisi di lapangan.

Berdasarkan metodologi yang ditetapkan, maka proses pengumpulan data dilakukan dengan cara sebagai berikut : 


\section{Pengumpulan Data Primer dan Sekunder}

\section{PENGUMPULAN DATA DAN INFORMASI}

1. Jumlah dan jenis perlintasan sebidang di jalur kereta api Cikarang-Cikampek.

2. Frekuensi perjalanan kereta api pada jalur kereta api Cikarang-Cikampek.

3. Headway perjalanan kereta api yang melintas pada jalur kereta api CikarangCikampek.

4. Volume lalu lintas harian rata-rata (LHR) pada perlintasan sebidang di jalur kereta api Cikarang-Cikampek.

5. Persepsi responden mengenai perlintasan sebidang.

\section{Pengolahan Data}

KOMPILASI DATA

Eksplorasi data primer dan sekunder

\begin{tabular}{|c|c|c|}
\hline $\begin{array}{l}\text { Menyusun strategi } \\
\text { agar peningkatan } \\
\text { frekuensi perjalanan } \\
\text { kereta api tidak } \\
\text { mengganggu } \\
\text { keselamatan }\end{array}$ & $\begin{array}{c}\text { Mengkaji } \\
\text { pelaksanaan } \\
\text { persyaratan dan } \\
\text { ketentuan mengenai } \\
\text { perlintasan sebidang }\end{array}$ & $\begin{array}{c}\text { Menentukan cara } \\
\text { mengatasi masalah } \\
\text { yang timbul dan } \\
\text { memprioritaskan } \\
\text { perlintasan sebidang } \\
\text { yang harus ditutup }\end{array}$ \\
\hline
\end{tabular}

\section{Analisis dan Rekomendasi}

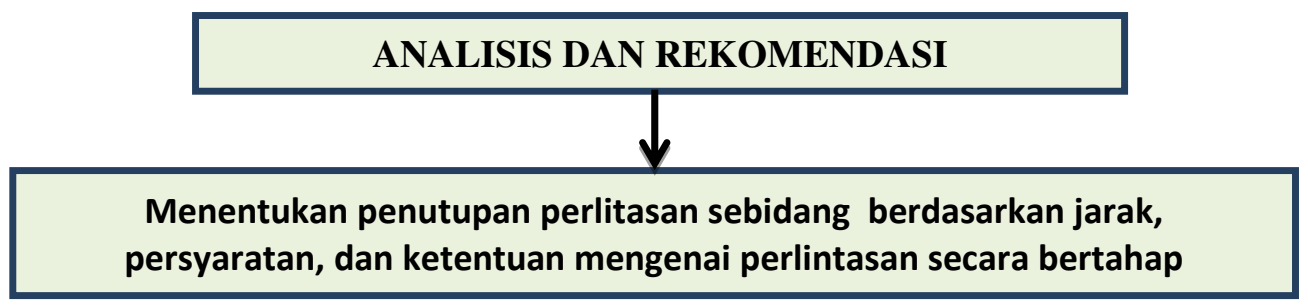

Untuk pelaksanaan penelitian ini akan dilakukan survei di Jalur Kereta Api Cikarang - Cikampek. Survei tersebut untuk mencari data-data yang akan dituangkan dalam formulir sebagai berikut :

1. Formulir 1. Jumlah dan Jarak antar Perlintasan Sebidang pada Jalur KA CikarangCikampek.

2. Formulir 2. Jumlah frekuensi dan headway perjalanan kereta api pada Jalur Kereta Api Cikarang-Cikampek per hari.

3. Formulir 3. Volume LHR dan Panjang Antrian di Perlintasan Sebidang pada Jalur Kereta Api Cikarang-Cikampek. 
4. Formulir 4. Data Perlintasan Sebidang pada Jalur Kereta Api Cikarang-Cikampek.

5. Daftar Pertanyaan mengenai persepsi pengguna jalan terhadap keselamatan di perlintasan sebidang.

\section{ANALISIS DAN PEMBAHASAN}

Jalur Kereta Api Cikarang-Cikampek merupakan bagian dari Jalur Kereta Api Utara (Jakarta-Cirebon-Semarang-Surabaya) dan Tengah (Cirebon-PurwokertoYogyakarta) serta Selatan (Jakarta-Bandung-Banjar-Yogyakarta-Madiun-Surabaya). Petak Jalan Rel Jalur Kereta Api Cikarang-Cikampek terdiri atas petak jalan rel, sebagai berikut :

1. Cikarang-Lemah Abang.

2. Lemah Abang-Gedung Gedeh.

3. Gedung Gedeh- Krawang.

4. Krawang-Klari.

5. Klari-Kosambi.

6. Kosambi-Dawuan.

7. Dawuan-Cikampek

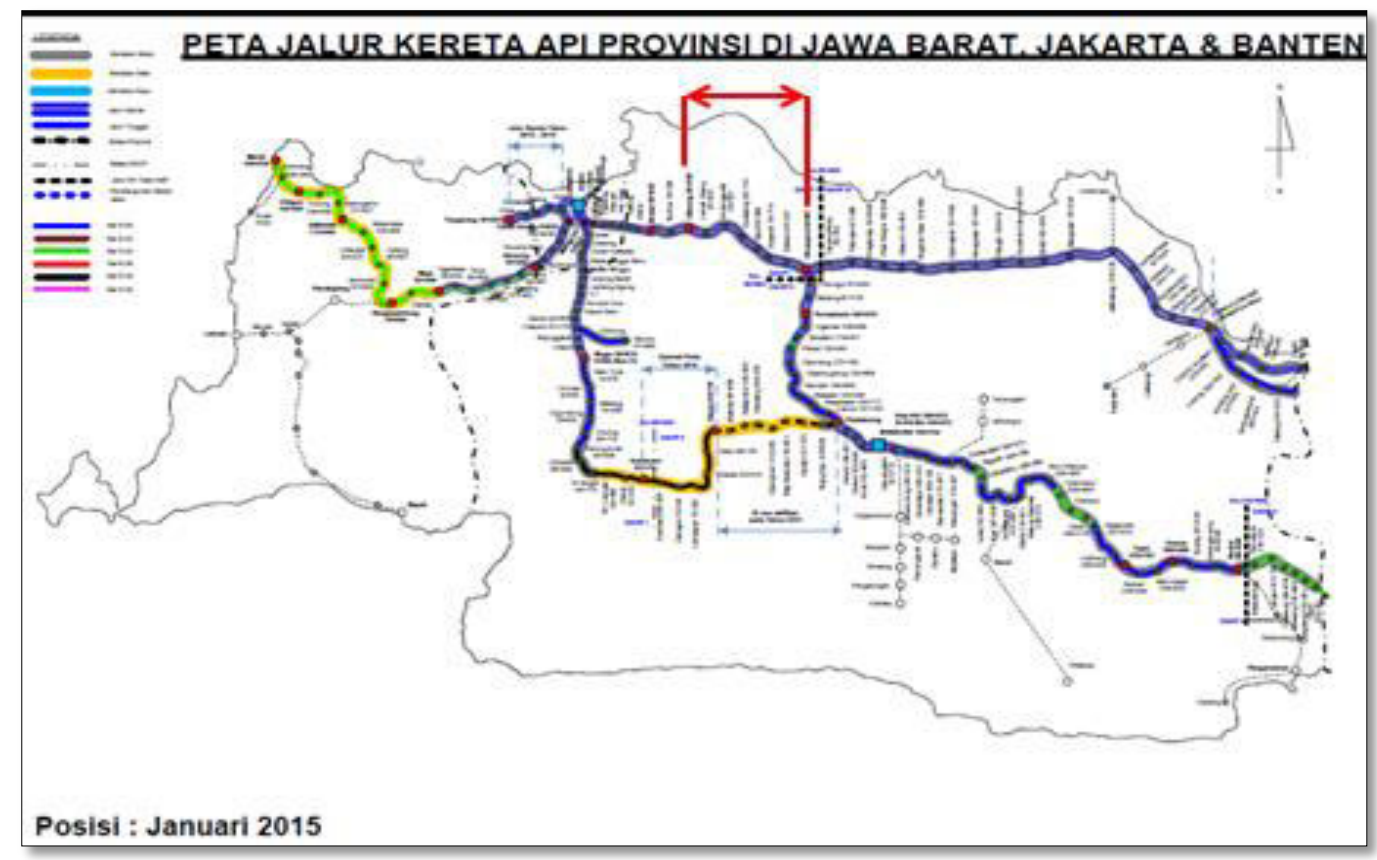

Gambar 1.1 Peta Jalur Kereta Api 
Pada petak-petak jalan rel tersebut terdapat perlintasan sebidang, sebagai berikut :

1. Cikarang-Lemah Abang
a. JPL-111 Jl. Yos Sudarso (Km 43+829).
b. JPL-118 Jl. Cibarusa (Km 47+562).

2. Lemah Abang-Kedung Gedeh
a. JPL-119 Jl. Raya Lemah Abang (Km 48+171).
b. JPL-122 Jl. Baypass Kojengkang (Km 50+076).
c. JPL-130 Jl. Baypass Kedung Gedeh (Km 56+368).

3. Kedung Gedeh-Krawang
a. JPL-134 Jl. Tanjung Pura (Km 58+385).
b. JPL-144a Jl. Baypass Krawang (Km 61+275).

4. Krawang-Klari
a. JPL-154 Jl. Tuparev (Km 63+400).
b. JPL-155a Jl. Teluk Jambe (Km 64+917).

5. Kosambi-Dawuan

a. JPL-174 Jl. Kosambi (Km 73+990).

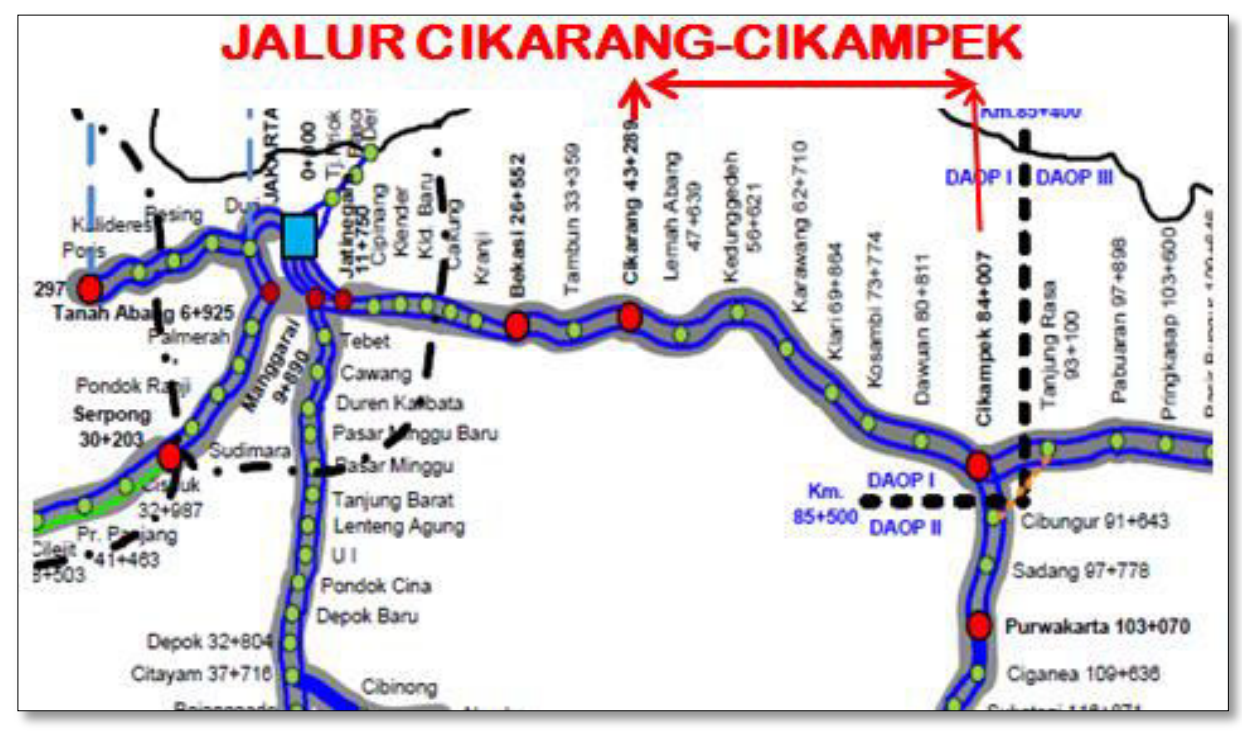

Gambar 1.2 Peta Jalur Kereta Api Cikarang - Cikampek 


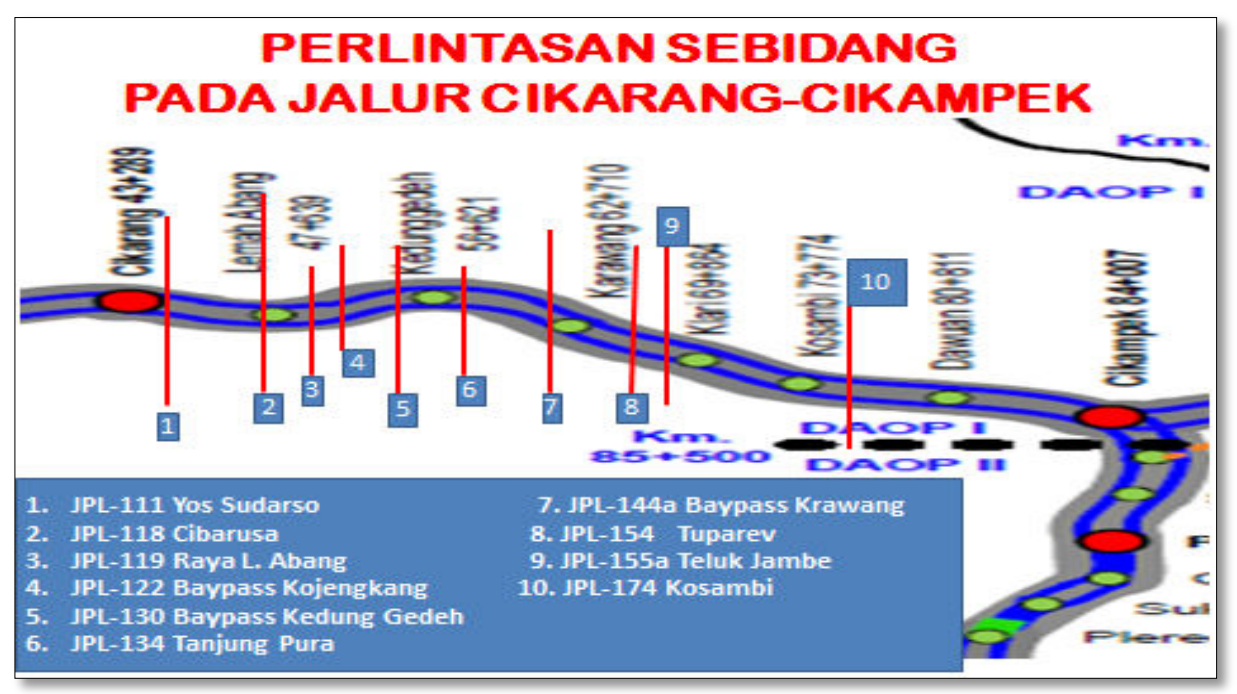

Gambar 1.3Peta Perlintasan Sebidang pada Jalur Kereta Api Cikarang -

Cikampek

Kondisi perlintasan sebidang pada Jalur Kereta Api Cikarang-Cikampek terdiri atas Perlintasan Sebidang Resmi Dijaga dan Perlintasan Sebidang Tidak Resmi/Liar.

\section{Perlintasan Sebidang Resmi Dijaga}

Pada Jalur KA Cikarang-Cikampek terdapat 10 perlintasan sebidang resmi dijaga dengan Jarak antar perlintasan sebidang, sebagai berikut :

a. JPL-111 Jl. Yos Sudarso dengan JPL-118 Jl. Cibarusah : $3.733 \mathrm{~m}$.

b. JPL-118 Jl. Cibarusah dengan JPL -119 Jl. Raya Lemah Abang : 609 m.

c. JPL-119 Jl. Cibarusa dengan JPL-122 Jl. Baypass Kojengkang : 1.905 m.

d. JPL-122 Jl. Baypass Kojengkang dengan JPL-130 Jl. Baypass Kedung Gedeh : $6.292 \mathrm{~m}$.

e. JPL-130 Jl. Baypass Kedung Gedeh dengan JPL-134 Jl. Tanjung Pura : 2.017 m.

f. JPL-134 Jl. Tanjung Pura dengan JPL-144a Jl. Baypass Krawang : 2.890 m.

g. JPL-144a Jl. Baypass Krawang dengan JPL-154 Jl. Tuparev : 2.125 m.

h. JPL-154 Jl. Tuparev dengan JPL-155a Jl. Teluk Jambe : $1.517 \mathrm{~m}$.

i. JPL-155a Jl. Teluk Jambe dengan JPL-174 Jl. Kosambi : 9.073 m.

\section{Perlintasan Sebidang Tidak Resmi/Liar}

Pada Jalur Kereta Api Cikarang-Cikampek, di samping terdapat perlintasan resmi dijaga, juga terdapat perlintasan sebidang liar sebanyak 15, yaitu antara perlintasan sebidang sebagai berikut:
a. Yos Sudarso - Cibarusah
$=5$ perlintasan liar
b. Lemah Abang - By Pass Konjengkang
$=1$ perlintasan liar
c. By Pass Konjengkang - Kedung Gedeh
$=2$ perlintasan liar 
d. Tanjung Pura - By Pass Karawang $\quad=1$ perlintasan liar.

e. By Pass Karawang - Tuparev $=1$ perlintasan liar

f. Teluk Jambe - Kosambi = 5 perlintasan liar

Tabel IV.1 Jumlah Dan Jarak Antar Perlintasan Sebidang Pada Jalur Ka Cikarang-

Cikampek

\begin{tabular}{|c|c|c|c|c|c|c|c|}
\hline No. & $\begin{array}{c}\text { Nama } \\
\text { Perlintasan } \\
\text { Sebidang } \\
\text { Resmi } \\
\text { Dijaga } \\
\end{array}$ & $\begin{array}{c}\text { Jarak } \\
\text { (m) }\end{array}$ & $\begin{array}{c}\text { Perlintasan } \\
\text { Sebidang } \\
\text { Liar }\end{array}$ & $\begin{array}{l}\text { Perlintasan } \\
\text { Sebidang } \\
\text { Sebelumnya }\end{array}$ & $\begin{array}{c}\text { Jarak } \\
(\mathrm{m})\end{array}$ & $\begin{array}{l}\text { Perlintasan } \\
\text { Sebidang } \\
\text { Sesudahnya }\end{array}$ & $\begin{array}{c}\text { Jarak } \\
\text { (m) }\end{array}$ \\
\hline 1. & $\begin{array}{l}\text { Yos Sudarso - } \\
\text { Cibarusah }\end{array}$ & 3.733 & $\begin{array}{l}\text { Liar-1 } \\
\text { Liar-2 } \\
\text { Liar-3 } \\
\text { Liar-4 } \\
\text { Liar-5 }\end{array}$ & $\begin{array}{l}\text { Yos Sudarso } \\
\text { Liar-1 } \\
\text { Liar-2 } \\
\text { Liar-3 } \\
\text { Liar-4 }\end{array}$ & $\begin{array}{l}613 \\
703 \\
247 \\
165 \\
338\end{array}$ & $\begin{array}{l}\text { Liar-2 } \\
\text { Liar-3 } \\
\text { Liar-4 } \\
\text { Liar-5 } \\
\text { Cibarusah }\end{array}$ & $\begin{array}{c}703 \\
247 \\
165 \\
338 \\
1.667\end{array}$ \\
\hline 2. & $\begin{array}{l}\text { Lemah Abang } \\
\text {-Bypass } \\
\text { Kojengkang }\end{array}$ & 1.905 & Liar-6 & Lemah Abang & 1.200 & $\begin{array}{l}\text { Bypass } \\
\text { Kojengkang }\end{array}$ & 705 \\
\hline 3. & $\begin{array}{l}\text { Bypass } \\
\text { Kojengkang - } \\
\text { Bypass } \\
\text { Kedung } \\
\text { Gedeh }\end{array}$ & 6.292 & $\begin{array}{l}\text { Liar-7 } \\
\text { Liar-8 }\end{array}$ & $\begin{array}{l}\text { Bypass } \\
\text { Kojengkang } \\
\text { Liar-7 }\end{array}$ & $\begin{array}{l}1.538 \\
435\end{array}$ & $\begin{array}{l}\text { Liar-8 } \\
\text { Bypass } \\
\text { Kedung } \\
\text { Gedeh }\end{array}$ & $\begin{array}{r}435 \\
4.319\end{array}$ \\
\hline 4. & $\begin{array}{l}\text { Tanjung Pura } \\
\text {-Bypass } \\
\text { Krawang }\end{array}$ & 2.890 & Liar-9 & Tanjung Pura & 1.493 & $\begin{array}{l}\text { Bypass } \\
\text { Krawang }\end{array}$ & 1.397 \\
\hline 5. & $\begin{array}{l}\text { Bypass } \\
\text { Krawang - } \\
\text { Tuparev }\end{array}$ & 2.125 & Liar-10 & $\begin{array}{l}\text { Bypass } \\
\text { Karawang }\end{array}$ & 829 & Tuparev & 1.296 \\
\hline 6. & $\begin{array}{l}\text { Teluk Jambe } \\
\text {-Kosambi }\end{array}$ & 9.073 & $\begin{array}{l}\text { Liar-11 } \\
\text { Liar-12 } \\
\text { Liar-13 } \\
\text { Liar-14 } \\
\text { Liar-15 }\end{array}$ & $\begin{array}{l}\text { Teluk Jambe } \\
\text { Liar-11 } \\
\text { Liar-12 } \\
\text { Liar-13 } \\
\text { Liar-1 }\end{array}$ & $\begin{array}{c}1.426 \\
243 \\
835 \\
2.885 \\
750\end{array}$ & $\begin{array}{l}\text { Liar-12 } \\
\text { Liar-13 } \\
\text { Liar-14 } \\
\text { Liar-15 } \\
\text { Kosambi }\end{array}$ & $\begin{array}{c}243 \\
835 \\
2.885 \\
750 \\
3.769\end{array}$ \\
\hline
\end{tabular}

Sumber: 1. Direktorat Keselamatan Perkeretaapian

2. Hasil Survei 


\section{Jumlah Frekuensi dan Headway Perjalanan Kereta Api}

a) Frekuensi dan headway Perjalanan Kereta Api Jalur Cikarang-Cikampek. Pada Jalur Kereta Api Cikarang-Cikampek sesuai dengan Grafik Perjalanan Kereta Api (Gapeka), frekuensi perjalanan kereta api sebanyak 89 dengan headway selama 16 menit dan realisasinya ternyata telah terpenuhi.

b) Frekuensi dan headway Perjalanan Kereta Api Jalur Cikampek-Cikarang. Begitu pula sebaliknya pada Jalur Kereta Api Cikampek-Cikarang sesuai Gapeka sebanyak 89 perjalanan kereta api dengan headway 16 menit dan realisasinya juga telah terpenuhi.

\section{Cara mengatasi permasalahan yang akan Timbul mengenai Perlintasan Sebidang pada Jalur Kereta Api Cikarang-Cikampek.}

Mengingat persyaratan teknis pada hampir semua perlintasan sebidang pada jalur kereta api Cikarang-Cikampek telah melebihi atau tidak sesuai ketentuan, maka untuk mengatasi supaya tidak menimbulkan kecelakaan dengan korban jiwa dan harta benda, secara bertahap dengan prioritas dilakukan penutupan untuk dibuat tidak sebidang. Demikian pula, untuk perlintasan sebidang liar sebanyak 10 (Liar-1, Liar-2, Liar-3, Liar-5, Liar-7, Liar-10, Liar-11, Liar-12, Liar-13, dan Liar-15) yang merupakan jalan setapak harus ditutup dan 5 perlintasan sebidang liar dibuat tidak sebidang secara bertahap (sesuai ketentuan Undang-undang Perkeretaapian).

a. Frekuensi telah mencapai sebanyak 178 perjalanan kereta api per hari dan headway-nya 8 menit (ketentuannya untuk frekuensi paling banyak 50 perjalanan per hari KA dan headway minimal setiap 30 menit).

b. Kepadatan arus lalu lintas (LHR) pada jalan-jalan yang melintasi rel kereta api pada jalur kereta api Cikarang-Cikampek telah mencapai paling sedikit 444 unit mobil dan 1.783 unit motor per jam pada saat sibuk (ketentuannya 1.000 s/d 1.500 kendaraan per hari).

c. Dari sebanyak 10 jalan perlintasan sebidang, dengan rincian 7 perlintasan sebidang merupakan jalan kelas I dan 1 perlintasan sebidang jalan kelas II (ketentuannya hanya pada jalan kelas III).

d. Terdapat 3 perlintasan sebidang yang panjang antrian kendaraan mencapai $120 \mathrm{~m}, 90 \mathrm{~m}$ dan $85 \mathrm{~m}$ pada saat pintu perlintasan ditutup.

e. Dari 10 perlintasan sebidang resmi dijaga yang ada terdapat 1 perlintasan sebidang yang kurang dari ketentuan yaitu 800 m (609 m) dan untuk perlintasan sebidang liar hampir semuanya kurang dari $800 \mathrm{~m}$. 


\section{KESIMPULAN DAN SARAN}

\section{Kesimpulan}

Jenis perlintasan sebidang yang ada pada jalur kereta api CikarangCikampek yaitu 10 perlintasan sebidang resmi dijaga dan 15 perlintasan tidak resmi/liar, dengan frekuensi sebanyak 178 perjalanan kereta api per hari dan headway-nya 8 menit (ketentuannya untuk frekuensi paling banyak 50 perjalanan per hari KA dan headway minimal setiap 30 menit).

Berdasarkan hasil survei yang dilakukan, persepsi pengguna jalan mengenai keselamatan di perlintasan sebidang cukup baik.Untuk mengatasi supaya tidak menimbulkan kecelakaan dengan korban jiwa dan harta benda, terhadap perlintasan sebidang resmi dijaga secara bertahap dengan prioritas dibuat tidak sebidang dan untuk perlintasan sebidang liar juga secara bertahap sebanyak 10 yang merupakan jalan setapak harus ditutup dan 5 perlintasan sebidang liar yang merupakan jalan yang telah diaspal atau dicor dibuat tidak sebidang.

\section{Saran}

a. Jenis perlintasan sebidang liar yang ada supaya dilakukan pengawasan untuk tidak ditambah lagi oleh masyarakat.

b. Kepadatan lalu lintas (LHR) yang terus meningkat, perlu terus diperhatikan agar rambu-rambu dan peringatan dipasang secara baik dan lengkap.

c. Perlu dilakukan sosialisasi mengenai keselamatan agar masyarakat di pinggir jalur kereta api tidak membuat atau menambah jumlah perlintasan sebidang liar.

d. Persepsi pengguna jalan mengenai keselamatan di perlintasan sebidang yang sudah cukup baik, perlu dipertahankan bahkan perlu ditingkatkan dengan cara dilakukan sosialisasi keselamatan.

e. Untuk mengatasi permasalahan yang timbul di perlintasan sebidang perlu terus diupayakan baik oleh pejabat di tingkat pusat maupun di tingkat provinsi dan kabupaten/kota yang wilayahnya dilalui jalur kereta api. 


\section{DAFTAR PUSTAKA}

1. Suryo Hapsoro Tri Utomo, 2007, "Studi Kecelakaan Kereta Api Indonesia”, Yayasan Bhakti Ganesha.

2. Suryo Hapsoro Tri Utomo, Ir. Ph.D, 2009, “Jalan Rel ”, Beta Offset, Yogyakarta.

3. Surakim H, 2014, "Kontruksi Jalan Rel dan Keselamatan Perjalanan Kereta Api”, Nuansa Cendekia, Bandung.

4. Badan Litbang Perhubungan, LIPI-ITB dan PT. Kereta Api Indonesia (Persero), 2005, "Naskah Akademik Rencana Induk Perkeretaapian Indonesia 2006-2030”, Jakarta.

5. Biro Hukum dan KSLN, Kementerian Perhubungan, Undang-undang No. 23 Tahun 2007 Tentang Perkeretaapian, Jakarta.

6. Direktorat Jenderal Perhubungan Darat, Departemen Perhubungan, 2009, Undangundang Republik Indonesia No. 22 tahun 2009 Tentang Lalu lintas dan Angkutan Jalan, Jakarta.

7. Biro Hukum dan KSLN, Kementerian Perhubungan, Peraturan Pemerintah No. 72 Tahun 2009 Tentang Lalu Lintas dan Angkutan Kereta Api, Jakarta.

8. Direktorat Jenderal Perkeretaapian, Kementerian Perhubungan, 2011, Peraturan Menteri Perhubungan No. PM.36 Tahun 2011 Tentang Perpotongan dan/atau Persinggungan anatara Jalur Kereta Api dengan Bangunan Lain, Jakarta.

9. Direktorat Jenderal Perhubungan Darat, Departemen Perhubungan, 2005, Peraturan Direktur Jeneral Perhubungan Darat No. SK.770/KA.401/DRJD/2005 Tentang Pedoman Teknis Perlintasan Sebidang antara Jalan dengan Jalur Kereta Api, Jakarta. 